\title{
nature
}

1 April 2004 Volume 428 Issue no 6982

\section{Playing a dangerous game}

The current US administration is edging towards a policy of developing new types of nuclear weapons. In today's uncertain world, the last thing we need is a renewed arms race among the world's nuclear powers.

$\mathrm{F}$ or the most hawkish of hawks, there's no nuke so good as a shiny, bells-and-whistles new nuke. And if you look at the fine print of the latest budget request for the US Department of Energy, it's clear that these birds of prey have been busy of late.

Any proposal to build new nuclear weapons is highly controversial - and would require the express permission of the US Congress. Yet in its projections for future years' spending, the 2005 energy department budget request is trying to sow the seeds of such developments. These projections call for "subsystem tests and a full system test" of a nuclear bomb proposed to vaporize deeply buried bunkers and other 'hardened' targets. Further on, one can find plans to rehabilitate old nuclear testing ranges in Nevada and to build a facility to massmanufacture plutonium triggers for detonating hydrogen bombs.

This activity is geared towards what the budget describes as the "stockpile of the future" — which, if a paper authored by four nuclearweapons scientists at the Los Alamos National Laboratory in New Mexico is anything to go by, could feature an arsenal of mini-nuclear weapons (B. L. Fearey et al. Comp. Strategy 22, 305-324; 2003). The authors argue that such weapons would deter rogue states from developing subterranean stores of chemical and biological weapons. But in describing the bombs as causing "reduced collateral damage", the paper raises the spectre of 'usable' nukes - a concept that causes the colour to drain from the cheeks of arms-control advocates.

Senior officials deny that there are any concrete plans to develop new weapons - merely "paper studies" to assess future options (see page 455). But seasoned observers see the current budget request as an attempt by the hawks within the Bush administration to pursue their new nukes agenda. These officials are backed by a minority of weapons scientists for whom life has lost meaning since their cold-war heyday, when they were given huge amounts of money to pursue the nuclear arms race with the Soviet Union.

This agenda is already damaging US national security. Russian politicians have responded with statements about developing nextgeneration strategic weapons. And if the United States and Russia start pursuing mini-nuclear weapons, it doesn't take much imagination to see that other countries, perhaps India and Pakistan, may follow suit. In an era in which the primary security threat seems to be from terrorism, the proliferation of portable nuclear weapons can't be a good idea.

Against this security background, America's nuclear-weapons scientists don't need to design new bombs to get back on the front lines of national defence. Many of them, for example, are members of top-secret nuclear search teams that watched over the New Year's celebrations in New York, Washington and other US cities this past winter. Others are working with the Department of Homeland Security to build detectors for ports and border crossings that can sniff out the faintest hint of radiation. And those working on stockpilestewardship programmes continue to support global stability.

These noble efforts will be undermined by the plans of a nostalgic few. Physicists who care about arms control, and officials in the Bush administration who don't share the hawks' enthusiasm for new weapons, should unite to nip these nuclear ambitions in the bud before they make the world even more dangerous than it already is.

\section{A fair deal for all}

Scientists in poorer countries have to pay over the odds for equipment and reagents. They deserve a helping hand.

W hen your government can't afford to match the research grants paid to rich labs in North America, Europe and Japan, it must be especially galling to have to pay more than your wealthy competitors for standard lab equipment and materials.

The extent of the problem is revealed this week by a Nature survey of researchers in Germany, Poland, the United States and Brazil (see page 453). On both sides of the Atlantic, the larger and more competitive market of the established scientific powers ensures that prices are driven down. But elsewhere, the poor get poorer.

What can researchers do to combat these harsh economics of scale? Sometimes it helps to negotiate just a little harder. One Polish group leader told Nature that he got a 35\% discount on centrifuges after confronting his local retailer with cheaper prices across the nearby German border. But Polish scientists have an ace up their sleeve: their country's imminent membership of the European Union means that they will soon be able to complain to officials in Brussels if they feel they are not benefiting from the continent's common market.

For scientists in other poorer countries, the best answer would be to negotiate transnational agreements to ensure that every research group similarly benefits from being part of a large, international market. Unfortunately, scientists and the bodies representing their interests can do little to affect the politics of international trade. But that doesn't mean we must accept the iniquitous status quo. The Stockholm-based International Foundation for Science, a nongovernmental organization that aims to help scientists in developing countries, provides one example: its grants, which totalled US $\$ 2.5 \mathrm{mil}-$ lion in 2003, included a $\$ 580,000$ purchasing service for scientific instruments and reagents. And the Pew Charitable Trusts, based in Philadelphia, have recently set up an initiative to make second-hand equipment available to their Latin American research fellows.

These are encouraging signs, but more and larger efforts are needed. In particular, there is a case for the United Nations Educational, Scientific and Cultural Organization (UNESCO) to get more deeply involved. UNESCO already has an agreement with some US non-profit organizations to promote the redistribution of used instruments, at low prices, to labs in poorer countries. It could expand these schemes, and consider providing a purchasing service for new equipment.

Finally, the affected scientists' national governments should remove customs barriers that can severely hamper the import of scientific instruments. Our survey found cases where it took researchers more than a year to get their hands on their equipment. When you've already paid over the odds, such delays are doubly frustrating. 